"Debate" is a new series offering opposing sides of a continuing, controversial issue in tobacco control. In this and the two responses that follow, the pros and cons of banning smoking outdoors are discussed by the Editor of Tobacco Control, Simon Chapman, physicist Fames Repace of Repace Associations in Bowie, Maryland, USA, and Michelle Bloch and Donald Shopland of the National Cancer Institute in Rockville, Maryland, USA

\title{
Banning smoking outdoors is seldom ethically justifiable
}

Several Australian hospitals are proposing to extend their indoor smoking bans outdoors. In 1996, the mayor of Friendship Heights, Maryland similarly sought to ban smoking in municipal parks and on sidewalks. A leading non-smokers' rights advocate in Sydney has attracted publicity for his proposal to take civil action to have his suburban tennis club ban smoking in outdoor spectator areas, typically occupied by a handful of people waiting for courts to become vacant. In Kerala and Goa in India, smoking is banned in public spaces such as beaches, attracting fines. ${ }^{1}$

Such proposals "push the envelope" of tobacco control into areas where questions need to be asked to ensure tobacco control policies are firmly anchored to scientific evidence and especially concern those who value the freedom of individuals to do what they please to the extent that this does not harm others. ${ }^{2}$ They invite consideration of whether zero tolerance of public exposure to toxic agents is a reasonable policy for civil societies and whether the loudly proclaimed exquisite sensitivities of a small minority should drive public policy.

Further, they invite us to reflect on the extent to which these policies risk alienating a large number of people who might otherwise be supportive of efforts to reduce environmental tobacco smoke (ETS) exposure in situations where there is significant risk or reduced amenity. In short, we need to ask whether efforts to prevent people smoking outdoors risk besmirching tobacco control advocates as the embodiment of intolerant, paternalistic busybodies, who, not content at protecting their own health, want to force smokers to not smoke even in circumstances where the effects of their smoking on others are immeasurably small. Such alienation may undermine support for other tobacco policies which, if implemented, may bring profound public health benefits to communities.

Why should smokers not be allowed to smoke in hospital grounds or other designated outdoor locations, well away from any reasonable prospect of harming (as distinct from visually offending) anyone? Advocates for outdoor bans advance a number of arguments, each of which raise significant ethical concerns. In this paper, I will rehearse their arguments, comment on why I believe they are ethically unsustainable, and conclude that there is justification for banning smoking in outdoor settings only in circumstances where exposure is sustained and significant such as in crowded spectator stadia.

\section{"Any exposure to ETS is harmful"}

At the heart of this debate is the question of at what level of exposure an agent might be reasonably deemed to be harmful. The 1997 Californian Environmental Protection Agency report on the health effects of exposure to ETS concluded that chronic, cumulative exposure-such as experienced by those living for years with smokers or who work in indoor environments where smoking is permittedcan increase the probability of dying from lung cancer by $20 \%$, from heart disease by $30 \%$, and can exacerbate asthma in children by 60-100\%. ${ }^{3}$ Acute exposure to ETS in healthy young adults has been shown to be associated with dose related impairment of endothelium dependent dilatation, suggesting early arterial damage. ${ }^{4}$ However, the transitory and fleeting exposure to others' smoking in open outdoor settings is not remotely comparable to that experienced in confined indoor settings such as were involved in the study cited above.

Comment: Risk aversion research shows that the risks individuals declare unacceptable are not necessarily those which have a high probability of a serious adverse outcome. ${ }^{5}$ Equally, people are often prepared to take risks that have high probabilities of negative outcomes. Of all the factors which have been identified as tending to increase public outrage, risks which are imposed rather than voluntary explain much of the variance in public perceptions. ${ }^{6}$ Passive smoking represents a quintessential imposed risk and, together with the possibility of dreaded outcomes (like lung cancer), often incites public demand for zero exposure. This explains why many will get incensed about exposure to a mere whiff of tobacco smoke, but will not hesitate to sit around a romantic smoky campfire where they will, by choice, be exposed to a large range and volume of carcinogenic particulates and gases.

The question thus remains as to whether zero tolerance of ETS throughout communities is reasonable public policy. The answer to 
this question can be only be guided by science. Science could attempt to quantify the health consequences of brief outdoor exposures and it would seem certain that for some rare individuals with exquisite sensitivity, an acute exposure at such a level might precipitate an adverse episode. Similar claims are sometimes made about a large range of environmental agents, but in general public policy is not based on cocooning such people from exposures that are inconsequential to nearly everyone.

\section{"Outdoor bans send an 'important} message' to the community"

Proponents of outdoor bans sometimes argue that such policies send an important "message" to communities that smoking is inconsistent with the sort of healthy environments that hospital directors might wish to promote. Smoking is not permitted anywhere on school grounds, so hospitals ought to set a similar example.

Comment: Schools are different to hospitals. Children do not have the same legal rights or autonomy as adults because they are not regarded as mature enough to make decisions such as choosing to not go to school, to buy alcohol or tobacco, or drive with safety. School authorities ban smoking by teachers on school grounds because of the important exemplar role teachers play with children. Such rules sometimes apply as conditions of employment in a hospital (such as requiring that health care staff should not smoke within sight of patients or visitors, just as some employers require for image reasons that their staff observe dress standards, do not smoke on duty, and so on). However, outdoor smoking does not harm staff or other patients, and because health care workers do not employ or somehow control patients and their visitors, there can be no justification for requiring them to not smoke outdoors.

If any message is sent to the community by an outdoor smoking ban, it may well be one that says health policy makers do not care about evidence of harm, but are more concerned to impose standards cut loose from any evidence base and indifferent to a vital ethical principle of respect for autonomy.

\section{"Other freedoms are curtailed in} hospitals ... why not smoking too?" We do not allow patients to go outdoors to drink alcohol or use illicit drugs. All patients already voluntarily forgo many freedoms while in hospitals, such as sexual activity. Why then should we allow them to go out to smoke?

Comment: Alcohol in moderation is not only harmless to health but demonstrably beneficial. ${ }^{7}$ When alcohol is restricted in hospitals it is because of the risk of anti-social intoxication. In fact, it is not uncommon to allow patients to drink alcohol while in hospital. Narcotic dependent people may be prescribed legal narcotics such as methadone in an attempt to mollify their cravings and allow treatment for other presenting problems. It is unlikely that there is ever any formal ban on sexual activity in hospitals. That sexual activity does not occur much is due to patients mostly not feeling sexually alert, and for lack of privacy. However, the real point here is why "forgoing freedoms" should be construed as virtuous and an argument for adding further restrictions. I would argue that hospitals should rather strive to create an atmosphere that while respecting the rights of others to a healthy and peaceful environment, allows as many normal freedoms as possible for often distressed patients and their visitors.

\section{"An enforced ban will be good for people's health"}

Patients would benefit by taking a break from smoking as a necessary part of their admission. Even a temporary period of restriction on smoking may improve a patient's prognosis and shorten their length of stay. In a publicly funded health system, there are obligations on patients to not unnecessarily complicate their recovery. They should therefore expect to be able not to smoke at all while in hospital.

Comment: Restrictions on smoking certainly do reduce smoking frequency and may also promote cessation. ${ }^{8}$ However, while this is an undoubted positive benefit, it cannot be used as a front end justification to restrict smoking. It is a fortunate byproduct of bans introduced because of Millean based concerns about stopping smokers harming others. ${ }^{9}$ The decision to bring benefit to oneself is a decision that should be up to the individual, not for others to impose.

Health care workers have a duty to offer assistance to those patients who want to quit (and I'd add, to try and persuade them). But there are many smokers who do not want to stop. When they are in hospital, they should not forfeit their rights to smoke if they want to, as long as they are not inflicting it on others. If they are unfortunate enough to be unable to get themselves outside to smoke, it would be a callous sort of health care that would say "you might want to smoke, but we so disapprove, we will not lift a finger to help you".

\section{"Escorting patients outside can cause} staff shortages leading to patient neglect" In times when there are staff shortages, or a generally low staff:patient ratio, if staff need to escort incapacitated patients outdoors to smoke, this could cause neglect of patients remaining on wards. Also, if staff were to not remain with such patients while they smoked outdoors, liability might arise if, for example, the patient fell or had a coronary event.

Comment: This is an argument that should be irrelevant to the smoking status of the patients escorted outdoors. Most hospitals allow, when time permits, staff to escort patients outdoors to get fresh air, sunshine, and a change of scenery. Such attention to patient wellbeing is regarded as compassionate. While such assistance to patients is not a "right", if we exorcised every aspect of patient care down to the level of their "rights", a stay in hospital would be an even more dehumanising experience than it often is. If such practices endanger patients who remain inside, the issue 
of absences per se should be addressed and not confounded by arguing that some reasons for going outdoors are somehow more deserving than others. Similarly, if there are risks in leaving patients unattended outdoors, such risks obviously exist for patients regardless of their smoking status.

\section{"Escorting staff will be exposed to patients' ETS"}

If staff have to remain near an incapacitated patient who is taken outside to smoke, this may force them to be exposed to ETS, which violates their occupational health and safety rights.

Comment: The level of ETS exposure a nurse would encounter in an outdoor setting while escorting a smoking patient would be minimal. If downwind of the plume, the nurse could move upwind, and so on. Concern about such levels of exposure borders on fumophobia. Nurses would be daily exposed to far greater risks from infectious diseases, despite infection control protocols.

\section{"Any form of air pollution should be stopped"}

There have been several attempts to quantify the contribution of cigarette smoke to air pollution. For example, Sanner estimated that a pack a day smoker pollutes the air with the same amount of mutagenic substances as when driving a car with a catalytic converter $35 \mathrm{~km}$ (22 miles). ${ }^{10}$

Comment: This startling conclusion appears counterintuitive, not least because the carcinogen benzene has been used to replace lead additives in fuel so that it can be used in catalytic converters. However, ASH UK's Clive Bates has pointed out that tobacco use is probably carbon neutral on a global level. Whatever carbon is put into the atmosphere during burning, equivalent carbon is sequestrated during tobacco growing as tobacco leaf fixes carbon from the air through photosynthesis. In a stable market, for each cigarette smoked, there is a tobacco leaf growing to produce the next cigarette. Non-carbon greenhouse emissions from tobacco burning such as oxides of nitrogen and methane are likely to be minute in the global scheme. ${ }^{11}$

\section{Conclusion}

A minority of people in tobacco control do not like to even see people smoking. Australian non-smokers rights activist Brian McBride wrote recently to some of his colleagues about outdoor smoking: "We must be prepared to fight the aesthetics and personal standards argument as well as the health argument, and that is what I intend to do. We should not underestimate the public awareness value of having smokers found guilty of negligent actions in all situations indoors or outdoors. The more cases we run the better."

I would argue that the two need to be kept thoroughly apart. Mixing "aesthetics" arguments with health arguments risks infecting tobacco control with the accusation that it is fundamentally the providence of people with capricious authoritarian proclivities, caring little for the scientific bedrock on which public health ought to stand.

Health promotion campaigns have often sought to portray smoking in ways different to those typically portrayed in tobacco advertising: smoking has been framed as desperate, disgusting, and slovenly. Don't such efforts also appeal to aesthetic rather than health concerns? Yes, but for my own part, I am comfortable with portrayals that seek to counterbalance the distortions of tobacco advertising with alternative definitions of reality. If a tobacco company can describe a carcinogenic product as "fresh", I am comfortable in countering that kissing a smoker is like licking an ashtray.

The world is full of people who do not like the "aesthetics" of others' different religions, race, sexual expression, modes of dress, or music. Too often these doctrines have found expression in paternalistic or downright oppressive regimes. We do not need authoritarian doctrines in tobacco control. SIMON CHAPMAN Editor

1 Anon. Goa to ban smoking in public from Oct 2. Deccan Herald (India). 1999; September 12.

2 Mill JS. On Liberty (1859). In: Wollheim R, ed. Three essays. Oxford: Oxford University Press, 1975:1-141.

3 Environmental Protection Agency, California. Office of Environmental Health Hazard Assessment. Health Effects of Exposure to Environmental Tobacco Smoke. Final Report 1997. www.oehha.org/scientific/ets/finalets.htm

4 Celermajer DS, Adams MR, Clarkson P et al. Passive smoking and impaired endothelium-dependent arterial dilata4.

5 Chapman S, Wutzke S. Not in our backyard: media coverage of community opposition to mobile phone towers: an application of Sandman's outrage model of risk perception. Aust NZ F Public Health 1997;21:614-20.

6 Covello VT. Informing people about risks from chemicals, radiation, and other toxic substances: a review of obstacles to public understanding and effective risk communication. In: Leiss W, ed. Prospects and problems in risk communication. Waterloo, Ontario: University of Waterloo Press, 1989:1-49.

7 Rimm EB, Klatsky A, Grobbee D, et al. Review of moderate alcohol consumption and reduced risk of coronary heart disease: is the effect due to beer, wine, or spirits. BMf 1996;312:731-6.

8 Chapman S, Borland R, Brownson R, et al. The impact of workplace smoking bans on declining cigarette consumption in Australia and the USA. Am $\mathcal{F}$ Public Health 1999;89:1018-23.

9 Goodin RE. The ethics of smoking. Ethics 1989;99:574624.

10 Sanner T. Air pollution from cigarette smoking and gasoline cars with catalytic converter. Abstract for the 8th World Conference on Tobacco or Health, Buenos Aires, Argentina; 30 March-3 April 1992. Abstract 330.

11 Bates C. Tobacco and greenhouse. Message posted to Globalink 26 June 1999. 